\title{
Performance Evaluation of PFC Boost Converters
}

\author{
Mohammed Asim ${ }^{1}$, Heena Parveen ${ }^{2}$, Dr. M. A. Mallick ${ }^{3}$, Ambreen Siddiqui ${ }^{4}$ \\ Assistant Professor, EE Department, Integral University, Lucknow, India ${ }^{1,4}$ \\ PG Student, EE Department, Integral University, Lucknow, India ${ }^{2}$ \\ Professor, EE Department, Integral University, Lucknow, India ${ }^{3}$
}

\begin{abstract}
The use of electronic equipment has increased in last few years. Therefore there is an immense need to ensure that the line current harmonics of any equipment connected to AC main line is limited to comply the regulatory standard. This requirement is satisfied by introducing some form of Power factor Correction (PFC) techniques to make the input current sinusoidal and reduce the harmonics. In this paper, a systematic review of power factor correction (PFC) boost rectifiers is presented. Performance comparison of conventional PFC boost rectifier at different duty ratio and voltages are shown and their efficiency is calculated.
\end{abstract}

Keywords: Power factor Correction (PFC), Efficiency, Active and Passive PFC, Boost Converter

\section{INTRODUCTION}

Power Factor (PF) is defined as a measure of how a load Passive PFC

draws power from the AC source. Leading or lagging PF The easiest way to control the harmonic current is to use causes transmission and distribution losses and also the a filter that allows current only at line frequency (50 or poor utilization of electrical power. A high power factor $60 \mathrm{~Hz}$ ). A passive PFC uses a filter at the AC input to means better utilization of electrical power, while a low correct poor power factor. The filter consists of some power factor represents poor utilization of electrical passive elements such as capacitors or ferrite core power. Due to leading or lagging power factor the inductors, and looks a non-linear device more like electrical energy is to be transferred back and forth a linear load. PFC circuit attains low Total Harmonic between the load and the source and only a part of this Distortion (THD). Also, because circuit operates at the electrical energy is utilized for real work. The nonlinear low line power frequency of $50 \mathrm{~Hz}$ or $60 \mathrm{~Hz}$, normally the loads such as DC drives, variable frequency drives, passive elements are bulky and heavy. Passive PFC programmable controllers, uninterruptible power supplies requires larger inductors or capacitors than an equivalent (UPSs), arc-type lighting has led to harmonic distortion power active PFC circuit also passive PFC is often less that reduces the power factor and as well as efficiency. effective than active PFC in improving the power factor.

And also degrades the performance of other equipment which is connected to the line. [1]. Total harmonic distortion gives how much of a waveform power is distorted caused by harmonics. It is defined as the ratio of power of all the harmonics with the power in the fundamental frequency.

THD is used to characterize nonlinearity of a system, while applying a single sinusoidal to it. When sinusoidal is applied to a nonlinear system it will produce an output with the same fundamental frequency as of the sinusoidal input, but will also generate harmonics at multiples of the fundamental frequency which termed as THD.

Many active and passive PFC technologies can be used to shape the current drawn by power supplies in order to comply with the requirements of international standards, such as IEC 61000-3-2 and IEEE-519.PFC technique can reduce the harmonics, increase the efficiency and capacity of power systems, and reduce customers' utility bill [2].

\section{POWER FACTOR CORRECTION TECHNIQUES}

Power Factor Correction (PFC) allows power distribution to operate at its maximum efficiency. PFC is classified into two categories: Passive and Active PFC [3].

\section{Active PFC}

An active PFC circuit consist of power electronic devices that control the amount of power drawn by a load in order to achieve a power factor as close as possible to unity. The preferable type of PFC is Active Power Factor Correction. Active PFC circuitry consists of some switching regulators with active elements such as ICs, FET, MOSFET and diodes. Active PFC increases power factor, reduces harmonics and automatically adjusts for AC input voltage. The drawback of this technique is it requires a complex EMI filter which is costly to build. Active PFC technique offers lower THD and is comparatively small in size and lighter than a passive PFC circuit. Active PFC perform several task such as active wave shaping of the input current, filtering of the high frequency switching, feedback control to regulate output voltage. Various Active topologies are used such as Buck converter, boost converter, fly back converter and other converter topologies out of which Boost converter topology is considered the best suited topology. [4]

\section{BOOST CONVERTER}

A Boost converter is simply a DC to DC converter in which the output voltage is greater than the input voltage. 
It is also called as step up converter. It is an active power factor correction topology which employs a boost converter associated with a conventional diode bridge rectifier, with the rectifier's output being fed to the boost converters input[5]. The circuit diagram of this topology is shown in Figure 1.

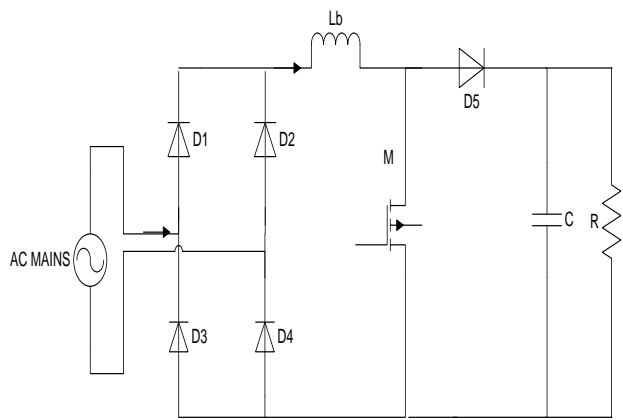

Fig. 1: Boost Converter

When the switch (M) is closed, the AC source converted into DC source energizes the inductor. Meanwhile, the capacitor maintains the output voltage using previously stored energy. When the switch is opened, both the DC source and the energy stored in the inductor will supply power to the load, thus boosting the output voltage.

A desired value of output voltage, higher than the input voltage can be obtained by controlling the duty ratio appropriately. The values of vital parameters are designed using the following consideration:

The duty ratio (D) of a typical boost converter is given by

$$
\mathrm{D}=\frac{(\mathrm{Vo}-\mathrm{Vin})}{\mathrm{Vo}_{\mathrm{o}}}
$$

The inductor shown can be designed using the expression

$$
\mathrm{L}=\frac{\mathrm{R} * \mathrm{D} *(1-\mathrm{D})^{2}}{2 \mathrm{f}}
$$

Where $\mathrm{R}=$ Load resistance and $\mathrm{f}=$ switching frequency The value of capacitance is given by the expression

$$
\mathrm{c}=\frac{\mathrm{Vo} * \mathrm{D}}{\mathrm{f} * \Delta \mathrm{V} * \mathrm{R}}
$$

Where $\Delta \mathrm{V}=$ Output voltage ripple

Boost converter topology has several advantages such as simple circuit, boosts the output voltage, the active switch is grounded, high efficiency.[6] This topology is extensively used for power factor correction applications in spite of its drawbacks, which are as high input current ripple, high switching and conduction losses, low efficiency at higher power levels due to diode bridge losses.[7]

\section{SIMULATION ANALYSIS}

Simulation circuit of conventional PFC boost rectifier is shown in Figure 2. Simulated line current waveforms of conventional PFC boost rectifier operating at $24 \mathrm{Vrms}$ line voltage are shown in Figure 3. The power factor is obtained as 0.8854 and efficiency is found to be $72.09 \%$ is found. The FFT analysis of input current waveform is shown in Figure 4 and is found to be $11.14 \%$.

The simulation of the model was done for $\mathrm{t}=0.02 \mathrm{~s}$ for input voltage $=24 \mathrm{~V}, 48 \mathrm{~V}, 115 \mathrm{~V}$ and $230 \mathrm{~V}$ at different

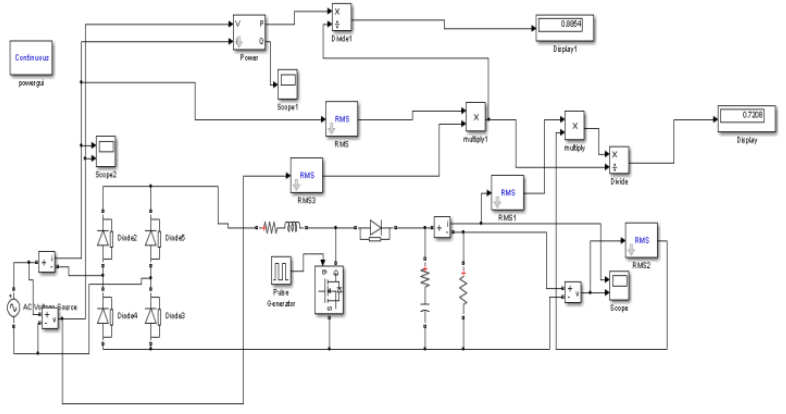

Fig. 2: Conventional Boost Converter

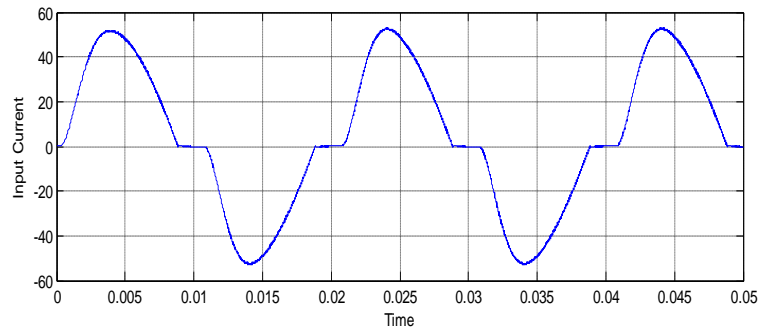

Fig. 3: Input current at duty ratio 80

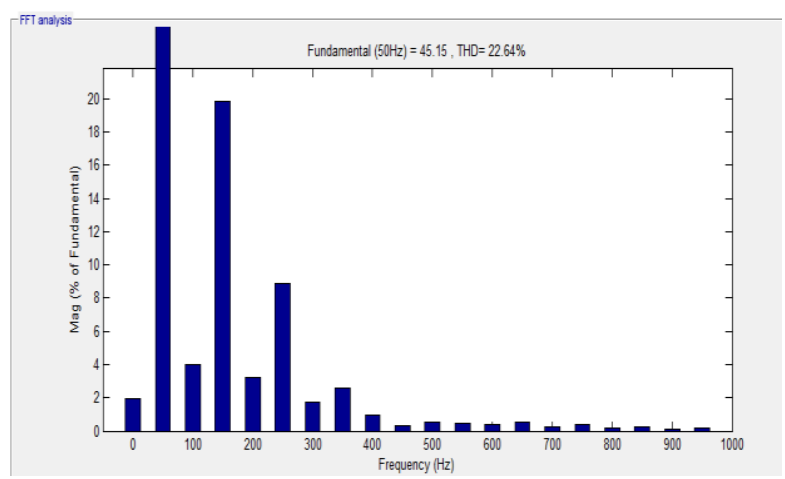

Fig. 4: FFT Analysis of conventional Boost Converter

duty ratios from 10 to 80 and the result are tabulated from table 1-4. Efficiency measurements are presented from figure 5-8.The table shows that as duty ratio increases the efficiency decreases as losses which include switching losses and conduction losses depend upon switching frequency and duty ratio. The calculation of switching losses includes the switching loss of the boost switch, the gate-drive losses. The switching loss of the boost switches is based on the turn-on loss due to the effective capacitance of the MOSFET. [8]

At 24 Volt

TABLE.1: EFFICIENCY VS DUTY RATIO

\begin{tabular}{|c|c|}
\hline Duty Ratio & Efficiency \\
\hline 10 & 0.7293 \\
\hline 20 & 0.7316 \\
\hline 30 & 0.7319 \\
\hline 40 & 0.7303 \\
\hline 50 & 0.724 \\
\hline 60 & 0.708 \\
\hline 70 & 0.668 \\
\hline 80 & 0.5575 \\
\hline
\end{tabular}


At 48 Volt

TABLE.2: EFFICIENCY VS DUTY RATIO

\begin{tabular}{|c|c|}
\hline Duty Ratio & Efficiency \\
\hline 10 & 0.7853 \\
\hline 20 & 0.7851 \\
\hline 30 & 0.7833 \\
\hline 40 & 0.7793 \\
\hline 50 & 0.7701 \\
\hline 60 & 0.7509 \\
\hline 70 & 0.7062 \\
\hline 80 & 0.5877 \\
\hline
\end{tabular}

At 115 Volt

TABLE.3: EFFICIENCY VS DUTY RATIO

\begin{tabular}{|c|c|}
\hline Duty Ratio & Efficiency \\
\hline 10 & 0.8183 \\
\hline 20 & 0.8167 \\
\hline 30 & 0.8137 \\
\hline 40 & 0.8082 \\
\hline 50 & 0.7973 \\
\hline 60 & 0.7762 \\
\hline 70 & 0.7286 \\
\hline 80 & 0.6054 \\
\hline
\end{tabular}

At 230 Volt

TABLE.4: EFFICIENCY VS DUTY RATIO

\begin{tabular}{|c|c|}
\hline Duty Ratio & Efficiency \\
\hline 10 & 0.8302 \\
\hline 20 & 0.8281 \\
\hline 30 & 0.8246 \\
\hline 40 & 0.8185 \\
\hline 50 & 0.8071 \\
\hline 60 & 0.7853 \\
\hline 70 & 0.7367 \\
\hline 80 & 0.6118 \\
\hline
\end{tabular}

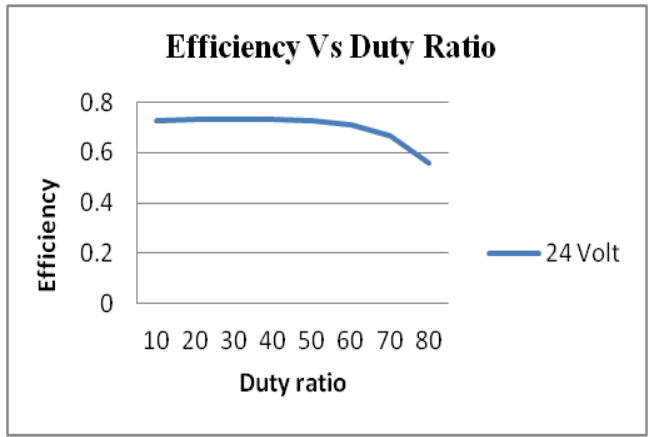

Fig: 5

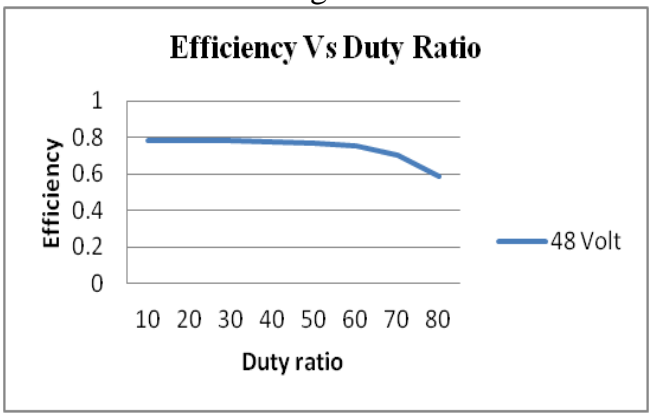

Fig: 6

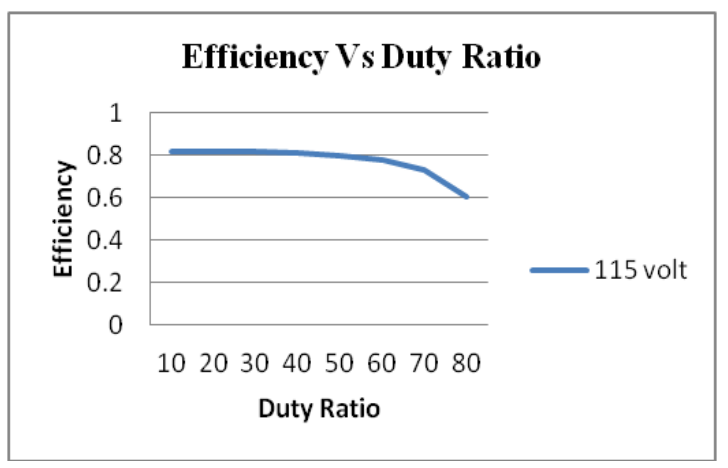

Fig: 7

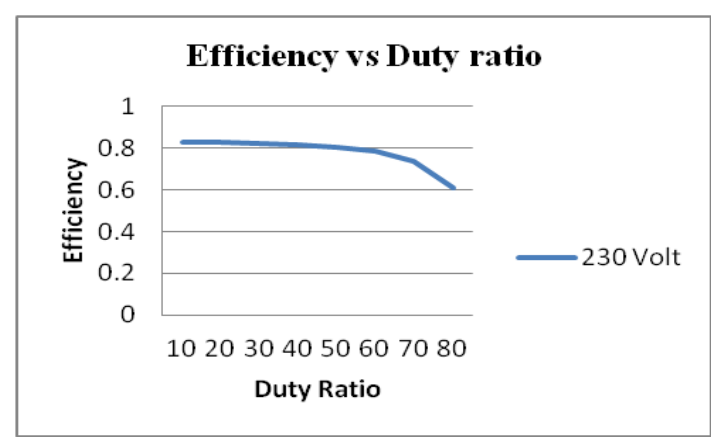

Fig.:8

\section{CONCLUSION}

A single-phase Bridgeless PFC Boost Converter is modelled and simulated using Matlab/Simulink. The boost converter not only improves the power factor of the circuit but it is also seen that as duty ratio changes the efficiency of the system changes as losses in the system which include switching losses and conduction losses varies. The efficiency is seen to increase with increase in input voltage and decrease with increase in duty ratio.

\section{ACKNOWLEDGMENT}

The authors are grateful to the Head, Department of Electrical Engineering, Integral University, Lucknow, UP, India, for providing all facilities for completion of this work. The work was done in the laboratory of Electrical Engineering Department, Integral University, Lucknow, UP, India.

\section{REFERENCES}

[1] Sridevi J., "A New Active Power Factor Correction Controller using Boost Converter," Research Journal of Engineering Sciences, vol. Vol. 2, no. 8, pp. 2278 - 9472, 7-11, August (2013).

[2] E. E. EL-Kholy, S.A.Mahmoud* and S.S.Shokralla H.Z.Azazi, "Review of Passive and Active Circuits for PowerFactor Correction in Single Phase, Low Power Ac-Dc converter," in 14th International Middle East Power Systems Conference (MEPCON'10), Cairo University, Egypt, December 2010, pp. 216224.

[3] Ch.M.Lakshmi P.Vijay Prasuna J.V.G.Rama Rao, "Improvement in Power factor \& THD using Dual Boost Converter," International Journal Of Engineering, vol. 2, no. 4, pp. 2368-2376, July-August 2012

[4] Supratim Basu And Math.H.J. Bollen, "A Novel Common Power Factor Correction Scheme For Homes and Officces," IEEE Transactions on Power Delivery, vol. 20, no. 3, pp. 2257-2263, July 2005

[5] M.S. Jamil asghar, Power Electronics, 1st ed. New Delhi, India: Prentice Hall of India(PHI), 2005. 
INTERNATIONAL JOURNAL OF INNOVATIVE RESEARCH IN ELECTRICAL, ELECTRONICS, INSTRUMENTATION AND CONTROL ENGINEERING Vol. 3, Issue 11, November 2015

[6] Dr.J.A.Makwana S.B.Mehta, "Power factor Improvement of SMPS using PFC," International Journal of Application or Onnovation in Engineering \& Management(IJAIEM), vol. 3, no. 4, pp. 299-305, April 2014.

[7] Gerry Moschopoulos and Praveen Jain, "Single Phase Single Stage Power Factor Corrected Converter Topologies," IEEE Transactions on Industrial Electronics, vol. 52, no. 1, pp. 23-35, February 2005.

[8] Member, IEEE, Yungtaek Jang, Senior Member, IEEE, and Milan M. Jovanovic', Fellow, IEEE Laszlo Huber, "Performance Evaluation of Bridgeless PFC Boost Rectifier," IEEE TRANSACTIONS ON POWER ELECTRONICS, vol. 23, no. 3, pp. 1381-1391, MAY 2008.. 